\title{
Integración y Migraciones. Las políticas migratorias de Argentina \\ y su relación con las políticas migratorias del MERCOSUR desde la perspectiva de los Derechos Humanos (2003-2013)*
}

por Carolina Urquiza**

\section{- Resumen}

Entre los años 2003 y 2013 Argentina ha tenido un indiscutible rol como impulsora de políticas más abiertas en relación al reconocimiento de los derechos de los migrantes, en un contexto internacional caracterizado por imponer cada vez más barreras a la migracióny, en muchos casos, violando los derechos de las personas migrantes. Los cambios en la política y normativa argentina en materia migratoria han tenido vinculación con el proceso de integración en el MERCOSUR.

La legislación argentina a través de la ley No 25.871 de 2004 marca un quiebre con la política anterior, dejando de lado la concepción de política migratoria restrictiva y de control,y dando lugar a una política respetuosa de los Derechos Humanos que adhiere y se adecua en forma progresiva a los postulados de los tratados internacionales. La normativa del MERCOSUR muestra ciertos avances en cuanto a las políticas que favorecen los derechos de los migrantes y tiene su correlato en las normas recientes de los estados parte. La ampliación de los derechos laborales, educativos y políticos de los migrantes mercosureños en Argentina muestra algunos avances. Sin embargo, la vinculación entre Argentina y el proceso de integración en materia migratoria y de Derechos Humanos es parcial y limitada. La falta de armonización de políticas al interior del MERCOSUR presenta un gran desafío, en tanto no todos los países suscriben y aplican esos avances de la misma forma, obstaculizando el efectivo respeto y aplicación de los derechos fundamentales de la población migrante.

\section{- Palabras Clave}

Políticas migratorias- Argentina- Proceso de Integración o MERCOSUR- Derechos Humanos- Tratados Internacionales

\section{Inglés | English}

\section{- Abstract}

Between the years 2003 and 2013, Argentine has had an undeniable role as a driving force for open politics related to the recognition of the migrants rights, in an international context characterized by imposing more and more barriers to the migration, violating those rights in many cases. Changes in politics and in the Argentinian regulations regarding migration rights have been connected to the process of the MERCOSUR integration from a human rights point of view.

The Argentinian legislation, Law No 25.871, shows a breakdown with foreign politics, leaving aside the conception of a restrictive and controlling migration politics and making room to a more respectful human rights politics which adheres and adjusts to the international treaties' postulates in a progressive way. The MERCOSUR regulations show certain progress regarding block's politics that are in favor of the migrants rights based on recent regulations from other part states. The expansion of the labor, educational and politics rights of the MERCOSUR migrants in Argentina shows quite progress. The connection between Argentina and the integration process concerning migration and human rights is partial and limited; the lack of harmony in politics inside the MERCOSUR presents a great challenge, given that not all countries suscribe and apply to this progress in the same way, preventing the effective respect and application of the fundamental rights of the migrant population.

\section{- Key words}

Migrant Policy- Argentine- Integration Process MERCOSUR- Human Rights- International Treaties

\footnotetext{
* El presente estudio surge como corolario de un trabajo de investigación presentado como Tesis Final en la Maestría de Cooperación e Integración Internacional, Universidad Nacional de Rosario.

** Magíster en Cooperación e Integración Internacional de la UNR y Licenciada en Relaciones Internacionales de la UNR, e-mail: urquiza408@hotmail.com
} 


\section{Introducción}

Este artículo aborda la política migratoria ${ }^{1}$ argentina y su relación con la política migratoria del MERCOSUR, desde una perspectiva que hace hincapié en el reconocimiento de los Derechos Humanos 2003-2013.

La política migratoria de la República Argentina a partir de la Ley de Migraciones No $^{\circ} 25.871$ (sancionada en el 2004 y reglamentada en el 2010), y la derogación de la norma represiva establecida por la última dictadura cívico militar" "Ley General de Migraciones y Fomento a la Inmigración" o "Videla"3 (1981), marca un quiebre con la anterior dejando de lado la concepción de política migratoria de control, expulsora, restrictiva en relación a los derechos de los migrantes; y da lugar a una política más abierta y respetuosa de los derechos fundamentales de los migrantes. Una de las más positivas reformas introducidas por la ley, es el reconocimiento del derecho humano a migrar.

La Ley No 25871 retoma la realidad migratoria imperante $y$, a su vez, adhiere a los postulados de los tratados internacionales en materia migratoria, respetando los Derechos Humanos. Así mismo, el país implementa el Programa de Normalización Documentaria Migratoria (2006) o Programa Patria Grande.
Paralelamente se evidencian avances normativos en el MERCOSUR $^{4}$ en materia social y especialmente migratoria. Cabe mencionar en este sentido el Acuerdo sobre Residencia para los Estados partes del MERCOSUR y asociados (2002) y el Foro Especializado Migratorio del MERCOSUR (FEM- 2004), entre otros.

Según datos de las Naciones Unidas ${ }^{5}$, más de 230 millones de personas o, expresado de otro modo, el 3,2 \% de la población mundial estaba viviendo fuera de sus países de nacimiento en 2013. El volumen y alcance que han adquirido las migraciones y sus efectos económicos, políticos, sociales y culturales, tanto a nivel global como en cada uno de los países involucrados, las ha convertido en uno de los fenómenos más importantes del mundo contemporáneo.

A su vez, la globalización o aldea global actual (interdependencia económica, política, cultural, etc. entre los Estados, revolución tecnológica y de las comunicaciones, achicamiento del espacio planetario, etc.), facilita el movimiento de contingentes humanos, a nivel internacional

Si bien las motivaciones de los desplazamientos son múltiples (motivaciones históricas, sociales, económicas, culturales, etc.), la principal sigue siendo la búsqueda de oportunidades laborales y de empleo para poder mejorar las condiciones y la calidad de vida propia y de sus familias.

1. Se sigue el concepto de Mármora (1988: 386) quien se refiere a las políticas migratorias afirmando que: "constituyen las propuestas y metas elaboradas desde el aparato estatal con el fin de influir sobre el tamaño, composición, origen, dirección, asentamiento e integración de los flujos migratorios espontáneos o como parte del global proceso de planificación económico-social ideado".

2. Durante el Proceso de Reorganización Nacional, nombre con el que se autodenominó la Dictadura cívico-militar, hubo cuatro juntas militares gobernantes sucesivas integradas por los titulares de cada una de las Fuerzas Armadas. La Primera Junta Militar de Gobierno (1976-1981) estuvo integrada por: el Teniente General Jorge Rafael Videla; el Brigadier General, Orlando Ramón Agosti; y el Almirante Emilio Eduardo Massera. La Segunda Junta Militar de Gobierno (1981) por el Teniente General Roberto Eduardo Viola; el Brigadier General, Omar Domingo Rubens Graffigna y el Almirante Amando Lambruschini. La Tercera Junta Militar de Gobierno (1981-1982) el Teniente General Leopoldo Fortunato Galtieri, el Brigadier General, Basilio Arturo Ignacio Lami Dozo, y el Almirante Jorge Isaac Anaya. La Cuarta Junta Militar de Gobierno (1982-1983) el Teniente General Cristino Nicolaides, el Brigadier General, Augusto Jorge Hughes; y el Almirante Rubén Oscar Franco.

3. La Ley Videla parte de la idea de la conveniencia de un texto único, global, que legisle sobre todos los aspectos del fenómeno migratorio, concepto de extranjería y población extranjera, sin olvidar el fomento de la inmigración que se declara una vez más, expresamente, debe ser europea.

4. A mediados de la década de los ochenta, la Argentina y el Brasil iniciaron un proceso de acercamiento que procuraba culminar con el histórico distanciamiento que había caracterizado las relaciones entre ambos países. Tal proceso, condujo a la firma del Acta de Buenos Aires de 1986, que tenía por objeto, según su preámbulo, "la integración de América Latina y la consolidación de la paz, la democracia, la seguridad y el desarrollo de la región". La presente acta se constituirá como uno de los antecedentes fundamentales del futuro Mercado Común del Sur (MERCOSUR).

5. Documento "La migración mundial en cifras" División de Población del Departamento de Asuntos Económicos y Sociales de Naciones Unidas (DESA) y OECD 2013. Disponible en: https://www.oecd.org/els/mig/SPANISH.pdf Consultado: 09/08/2014. 
En este escenario, las redes migratorias, definidas como lazos interpersonales que vinculan a migrantes, ex migrantes y no migrantes en los lugares de origen y destino a través de lazos sanguíneos, amistad o vecindad, cumplieron un rol esencial dado que propiciaron la prolongación de los flujos migratorios a través del tiempo (MASSEY et al., 1993).

Igualmente en los países del Cono Sur las migraciones estuvieron vinculadas al desarrollo de la población y a los mercados de trabajo, reflejando los actuales desequilibrios, esencialmente económicos-laborales al igual que sociales y políticos entre países y regiones (MAGUID, 2005). Así los trabajadores migrantes de esta zona salen de sus lugares de origen en busca de mejores perspectivas de laborales y de calidad de vida y arriban a mercados de empleo que reclutan este tipo de fuerza laboral.

En la región el fenómeno inmigratorio ha estado presente a los largo de la historia, sin embargo ha recobrado especial relevancia en la agenda de los gobiernos en la última década, ya que cambiaron e intensifican los patrones migratorios intrarregionales. Es decir, las migraciones se producen al interior de la misma región debido, en parte, a la crisis de los países más desarrollados y de destino tradicionales, y a las restricciones que imponen al ingreso de extranjeros. Cabe aclarar existen tres patrones migratorios en la región: la inmigración de ultramar, que se encuentra en un momento de desaceleración; la extrarregional, ya que existen flujos de migrantes en dirección de los países desarrollados (Estados Unidos, Canadá, Japón y países europeos) y la migración intrarregional, siendo esta última motivo de estudio y la que afecta a la región (NOVICK, 2005).
Además, la migración comenzó paulatinamente a ser un tema de interés y preocupación por parte de los Estados, organizaciones internacionales y a ocupar la agenda de los Derechos Humanos. Pérez Luño define a los Derechos Humanos como:

"conjunto de facultades e instituciones que, en cada momento histórico, concretan las exigencias de la dignidad, la libertad y la igualdad humana, las cuales deben ser reconocidas positivamente por los ordenamientos jurídicos a nivel nacional e internacional" (Citado por Muguerza, 1989:21)

A pesar de los avances en materia de derecho y la protección jurídica de los Derechos Humanos a nivel internacional y regional, se observa que la realidad dista mucho del respeto a los mencionados derechos de los migrantes. ${ }^{6}$

En este sentido, los migrantes tienen que atravesar diferentes situaciones de violaciones de sus derechos, tales como discriminación por género, burocracias que obstaculizan trámites, escasa solidaridad de quienes padecen situaciones de pobreza y violencia que acompaña el cruce de las fronteras en algunos territorios y que afecta especialmente a mujeres y niños. A su vez, la integración parcial de los inmigrantes en los países de destino se presenta en condiciones de desprotección social y falta de derechos laborales. Sumado al ingreso de los inmigrantes en condiciones administrativas irregulares, todos obstáculos para ejercicio de los derechos y acceso a distintos servicios. En muchos casos siguen sufriendo comportamientos o actitudes xenófobas, discriminatorias, de exclusión de la sociedad en general. Persisten discursos arraigados en torno a la imagen social que se construye del migrante, y dicha construcción depende de las posibilidades reales de inte-

6. En este sentido cabe mencionar la "Convención para la Protección de los Derechos de los Trabajadores Migrantes y de sus Familias", aprobada en 1990 y en vigor desde 2003. Dicha Convención complementa los Convenios sobre trabajadores migrantes de 1949, y 1975. Entre los tratados internacionales se encuentra también la "Convención sobre la eliminación de todas las formas de discriminación contra la mujer" (CEDAW) de 1979, que pone énfasis en la protección de los derechos humanos de las mujeres y los niños migrantes, dada su especial vulnerabilidad. Asimismo, la “Convención sobre los Derechos del Niño" de 1989, protege a los menores de edad, por su especial situación de vulnerabilidad e indefensión. Finalmente, existen varios tratados relativos a la tortura y el tráfico de personas, como la "Convención contra la Tortura y otros Tratos o Penas Crueles, Inhumanos o Degradantes" de 1984, complementada a través de su Protocolo Facultativo de 2002; y la "Convención contra el crimen transnacional organizado" y su Protocolo complementario para Prevenir, Suprimir y Castigar el Tráfico de Personas, especialmente de Mujeres y Niños (Protocolo de Palermo), en vigor desde 2003, en los que se definen la lucha contra el tráfico y la trata de seres humanos como una forma moderna de esclavitud. Cabe mencionar la Convención sobre el Estatuto de los Refugiados, 1951; entrada en vigor el 22 de abril de 1954 Convención sobre los Refugiados el Protocolo sobre el Estatuto de los Refugiados, 1967; entrada en vigor el 4 de octubre de 1967. 
grarse al nuevo contexto en condiciones de igualdad de oportunidades y de reconocimiento de derechos al igual que los nacionales.

A su vez, la corriente mundial en materia de derechos migratorios se caracteriza por una tendencia hacia la criminalización de la migración. Hechos tales como el atentado terrorista del 11 de septiembre de 2001 en Estados Unidos y la crisis económico- financiera de $2008^{7}$ refuerzan dicha tendencia, poniendo énfasis en la seguridad y la lucha contra el terrorismo o en una visión utilitarista ${ }^{8}(\mathrm{DE}$ LUCAS, 2004) con que se revisten muchas normativas migratorias nacionales. De allí que existe una creciente inclinación a nivel internacional y regional por parte de los Estados, especialmente Estados Unidos y países pertenecientes a la Unión Europea a implementar políticas migratorias restrictivas o barreras hacia la libre circulación de personas, implicando en muchos casos la desprotección de los Derechos Humanos de los migrantes.

De lo expuesto se evidencia, que las políticas migratorias argentinas (2003-2013) van a contratiempo de la tendencia predominante que se presenta en el contexto internacional, caracterizado por implementar políticas restrictivas a nivel nacional o regional.

\section{Cambios en la política migratoria ar- gentina y su nuevo rol como impulsor de políticas respetuosas de los Derechos Humanos (DDHH)}

Argentina ha sido tradicionalmente receptor de inmigrantes internacionales, proceso central en la formación histórica del país tanto a nivel político, económico como social y cultural. Las migraciones internacionales en el país ocuparon un lugar central en la conformación del Estado, desde fines del siglo XIX. A partir de mediados del siglo XX, con la declinación de la inmigración europea, la presencia de inmigrantes de países limítrofes comienza a cobrar mayor peso cuantitativo sobre el total de la población extranjera9. Está situación se vio fortalecida desde los primeros años del nuevo milenio, transformándose en el principal país receptor de migrantes provenientes de la región ${ }^{10}$. En comparación con los países de América Latina, Argentina mantiene una situación más favorable respecto al PBI per cápita, al acceso al empleo, la disponibilidad de bienes y servicios públicos y la cobertura de la protección social, todos beneficios que son valorados por los inmigrantes y que a su vez son evaluados a través del Índice de Desarrollo Humano (IDH) del Programa de las Naciones Unidas para el Desarrollo (PNUD). ${ }^{11}$

En la actualidad, a pesar de ser cuantitativamente considerable el número de inmigrantes en la Argentina (alrededor de 1.000 .800 personas), es poco gravitante, representando el 4,5\% de la población total, del cual el $84,6 \%$ corresponde a la de los países que limitan con la Argenti$\mathrm{na}^{12}$, como fue señalado anteriormente.

Argentina a través de su cambio en la legislación ${ }^{13}$ marca una nueva impronta y le da un nuevo sentido a las políticas migratorias en el campo de los Derechos Humanos. Una de las más positivas reformas introducidas por la ley, es el reconocimiento del derecho humano a migrar. La Ley de Migraciones No 25.871, en su artículo 4 dice:

"El derecho a la migración es esencial e inalienable de la persona y la República Argentina lo garantiza sobre la base de los principios de igualdad y universalidad". ${ }^{14}$

13. A mediados de los noventa comienzan a surgir proyectos de ley que hasta el momento sin éxito pretenden cambiar la ley militar en materia migratoria y que son acordes con el respeto de los Derechos Humanos fundamentales, hecho que demuestra la intensa actividad parlamentaria. 14. Entre los fundamentos jurídicos sustituye la calificación de "ilegal" por "irregular" y reconoce igualdad de derechos entre nacionales y extranjeros. 
Este artículo no sólo reconoce e introduce en el derecho interno lo establecido en la Declaración Universal de los Derechos Humanos; sino que, además, establece la obligación del Estado de garantizar ese derecho.

Paralelamente, existen avances en el marco del proceso de integración mercosureño con la propuesta de Argentina de implementar el Programa Nacional de Regularización Migratoria para Extranjeros del MERCOSUR ampliado, "Patria Grande" (anunciado en 2005 e implementado en 2006). Dicho Programa está dirigido a los extranjeros de los Estados parte ${ }^{15}$ y asociados ${ }^{16}$ del MERCOSUR, y permite el acceso a la legalidad de aquellos nativos a la región, que se encuentren de forma irregular en algún país del bloque al mismo tiempo que posibilita la gobernabilidad de los futuros flujos migratorios y la transparencia de los mercados laborales de los Estados parte ${ }^{17}$.

Cabe mencionar, además, que Argentina adhiere en el año 2004 a la "Convención para la protección de los Trabajadores Migratorios y sus familiares" (ratificada en 2007) ${ }^{18}$; que adopta la primera ley de refugiados "Ley No 26.165" (2006), y aprueba la Ley No 26.364 para combatir el tráfico y la trata de personas (2008), entre otros ${ }^{19}$. El país tuvo un rol protagónico ya que fue quien tuvo la iniciativa en 2002 a la hora de concebir el "Acuerdo sobre Residencia para Nacionales de los Estados parte del MERCOSUR, Bolivia y Chile", el cual fue finalmente internalizado por todos los países en 2009, tras la notificación de Paraguay.

Estas acciones se enmarcan en una política exterior argentina, que prioriza el plano regional y la integración y la defensa de los Derechos Humanos, con los objetivos de insertarse en el plano internacional y a su vez ganarse el apoyo moral de la comunidad regional y mundial.

Asimismo, cabe referir a la activa participación de las asociaciones de la sociedad civil en la elaboración de dicha legislación, a través de negociaciones previas a la sanción ${ }^{20}$. Finalmente, a mediados de los noventa, comienzan a surgir proyectos de ley que pretenden cambiar la ley militar en materia migratoria y que son acordes con el respeto de los Derechos Humanos fundamentales, hecho que demuestra la intensa actividad parlamentaria (NOVICK, 2006).

15. Los Estados parte que conforman el MERCOSUR son Argentina, Brasil, Uruguay, Paraguay, Venezuela (suspendida indefinidamente en 2017 por "ruptura del orden democrático") y Bolivia (en proceso de adhesión).

16. Mientras que los Estados asociados son: Chile, Ecuador, Perú, Colombia, Guyana, Surinam.

17. Programa Patria Grande de acuerdo a la base de datos: Asientos Registro Nacional de Admisión de Extranjeros (Ministerio del Interior DNM 2010): - 423.697 fue la cantidad de personas inscriptas en el Programa; se otorgaron 98.539 radicaciones permanentes; se otorgaron 126.385 radicaciones temporarias; 187.759 de los inscriptos no completaron la documentación requerida para el trámite de regularización. Para un desarrollo detallado sobre las radicaciones temporarias y permanentes resueltas por nacionalidad 2004-2014, ver DNM y Ministerio del Interior y Transporte-Informe especial 2004-Síntesis estadística de Radicaciones.

18. La Convención sobre la protección de los derechos de todos los Trabajadores Migratorios y de sus familiares fue abierta a la firma el 18 de diciembre de 1990. Fue firmada por Argentina el 10 de agosto de 2004, esto es, luego de su entrada en vigor (el 1 de julio de 2003). Argentina depositó el instrumento de ratificación el 23 de febrero de 2007. En efecto, el artículo 32 reconoce al trabajador y a sus familiares el derecho a transferir remesas, con independencia de su situación frente al Estado de recepción. Esto supone una mejora respecto a la situación prevista en los Acuerdo sobre Residencia, donde sólo las personas que hubieran obtenido su residencia conforme al mismo gozarían de tal derecho (art. 9 punto 5).

19. Tales como la participación de las asociaciones de inmigrantes y refugiados previstas en las nuevas leyes, la creación del Programa Raíces (retorno y vinculación con investigadores y científicos argentinos emigrados) y su posterior confirmación como política de Estado, creación del Programa Provincia 25, de enlace y unión con argentinos emigrados; aprobación de la ley de Prevención y Sanción de la Trata de Personas y Asistencia a sus Víctimas; creación de la Comisión Nacional para los Refugiados; la firma de acuerdos migratorios bilaterales con Chile y el Perú; aprobación del Acuerdo contra el tráfico ilícito de migrantes entre los Estados parte del MERCOSUR.

20. A mediados de la década del noventa, ya creadas las Comisiones de Población en ambas cámaras del Poder Legislativo -Senadores y Diputados- y dadas las gestiones realizadas por las ONGs, organizaciones de las colectividades extranjeras, instituciones religiosas, grupos académicos, etc., surgen en el Congreso nacional proyectos que pretenden modificar la ley militar: Cafiero (1996 y 1998); Carrió (1996); Mondelo y Dellepiane (1997); Pichetto (1998), etc. También se presentaron otros que proponían derogar la ley militar y reemplazarla por una nueva: el del diputado Muñoz (1994); diputado Totto(1995); diputada Mondelo (1999), y el de la Comisión de Población de la Cámara de Diputados (1999). Fueron todos intentos que demuestran la intensa actividad parlamentaria: la sociedad civil rechazaba la vigencia de normas dictatoriales durante gobiernos democráticos (NOVICK, 2006). 


\section{Avances y desafíos en cuanto al dere- cho al trabajo, a la educación y derecho a votar de los migrantes limítrofes en Argentina}

El reconocimiento que otorga Argentina al derecho a migrar como derecho inalienable a la persona humana es innovador en la medida que extiende los derechos constitucionales y humanos a todos los migrantes dentro del país.

El derecho a migrar como derecho humano, exige igualdad de trato para los migrantes, sin perjuicio de la nacionalidad y la condición migratoria eintroduce en el derecho interno lo establecido en la Declaración Universal de los Derechos Humanos. El Estado argentino es el responsable de garantizar esos derechos.

Argentina implementa políticas migratorias abiertas que benefician a toda la población migrante y especialmente a los provenientes de los países pertenecientes al MERCOSUR. Asimismo, establece una serie de acciones que facilitan la admisión, el ingreso y la permanencia en el país, así como su acceso a servicios sociales básicos de salud, educación, justicia, trabajo, empleo y seguridad social y al voto. ${ }^{21} \mathrm{El}$ artículo 6 de la Ley establece:

"El Estado en todas sus jurisdicciones, asegurará el acceso igualitario a los inmigrantes y sus familias en las mismas condiciones de protección, amparo y derechos de losque gozan los nacionales, en particular lo referido a servicios sociales, bienes públicos, salud, educación, justicia, trabajo, empleo y seguridad social."
En este trabajo de investigación se hace especial mención al derecho al trabajo, a la educación y al voto. ${ }^{22}$ En estos aspectos existen ciertos progresos y consensos en relación a las políticas migratorias.

Con respecto al derecho humano al trabajo ${ }^{23}$ la nueva normativa en Argentina persigue como objetivo la protección de los trabajadores migrantes, de allí que busca la inserción e integración laboral de los inmigrantes que residan en forma legal para el mejor aprovechamiento de sus capacidades personales y laborales, a fin de contribuir al desarrollo económico y social de país. A pesar que la ley establece una serie de multas e infracciones para la actividad laboral irregular, procura la defensa de sus derechos como trabajadores evitando así contratos irregulares o que sean sometidos a situaciones de explotación. También garantiza condiciones laborales, prestaciones, cotizaciones de seguros, indemnizaciones, fondeos de retiro, etc., para los trabajadores sin importar su condición migratoria.

En relación a este derecho se puede afirmar que en la práctica el cambio de legislación en Argentina al igual que el Programa Patria Grande ${ }^{24}$ permitió mejorar las condiciones de laborales de los inmigrantes ${ }^{25}$, ya que disminuyeron las tasas de desempleo y subempleo y también disminuyó el trabajo no registrado. ${ }^{26} \mathrm{~A}$ pesar que aún se advierten problemas laborales, ya que sigue existiendo un alto nivel de empleo no registrado con los obstáculos que dicha condición conlleva, como ser la falta de cobertura en la seguridad social y otros indicadores de precariedad laboral tales como menores ingresos, discriminación, etc.

21. Con respecto a la elección y justificación de estos tres derechos, en el trabajo de investigación, tales como son el trabajo, educación y voto, se debe a la relevancia de los aspectos y al acceso a la información disponible para así abordar su estudio.

22. En relación a la búsqueda de representación en la sociedad de destino, también existe un amplio abanico de los derechos políticos, que van desde el derecho al voto, derecho a ser electo, derecho a asociarse, derecho a reunirse con fines políticos, derecho a acceder a cargos públicos, entre otros. En dicha investigación nos dedicamos en particular al reconocimiento de los derechos electorales a los extranjeros.

23. "En el marco del derecho laboral y mucho más ampliamente en el del derecho universal de los Derechos Humanos, la migración laboral es el ejercicio de la libertad de movimiento, para el goce del derecho al trabajo y del principio de igualdad. Se trata del derecho a migrar para trabajar en igualdad de condiciones con los nacionales del país de destino". (ERMIDA URIARTE, 2009: 33)

24. Con el Programa Patria Grande se inscribieron más de 417 mil inmigrantes procedentes de países del MERCOSUR, con el fin de regularizar su situación migratoria. A partir de su aplicación, la obtención de la residencia migratoria legal permitió a muchos inmigrantes acceder a un empleo formal, probablemente porque pasaron a ser trabajadores registrados en un empleo en el que ya se desempeñaban pero queno podían formalizar por falta de documentación migratoria legal o, posiblemente, accediendo a los nuevos empleos formales que se generaron en el país en los últimos años 25. En la última etapa de 2003-2010 coincide y se inicia una recuperación económica del país luego se fortaleció un proceso de crecimiento con significativas mejoras del empleo ya sea para los nativos como para los inmigrantes, dejando atrás la crisis que sufrió el país de 2001 donde los trabajadores inmigrantes sufrían una situación de gran precariedad laboral y donde casi el 72\% no tenían cobertura de la seguridad social. (BAER; BENITEZ y CONTARTESE, 2012).

26. Para profundizar consultar: Fuentes: Informe de la Organización Internacional para las Migraciones (OIM) (2012) según datos de la Encuesta Permanente de Hogares (EPH), INDEC. 
Acerca del acceso a los derechos sociales, más específicamente a la educación, en Argentina al igual que en la mayoría de los países democráticos y de la región, no se niegan dichos derechos. En la Ley migratoria se confirma que el Estado es quien asegurará la admisión igualitaria a los inmigrantes y sus familias en las mismas condiciones de protección, amparo y derechos de los que gozan los nacionales. A su vez establece el acceso a la educación de los inmigrantes en modo irrestricto, ya que en ningún caso la irregularidad migratoria de un extranjero impedirá su ingreso como alumno en un establecimiento educativo.

En la práctica, se pueden detectar algunos progresos en cuanto al ingreso al sistema educativo a partir de la nueva ley, sin embargo estos resultados son reducidos ya que como lo demuestran los datos, existe una asistencia masiva al sistema educativo primario y secundario, en las edades más tempranas y que luego decae en edades más avanzadas, es decir a la posibilidad de estudiar a nivel terciario o universitario. ${ }^{27}$

En relación al derecho político al sufragio por parte del extranjero residente en el país, la nueva ley de migraciones afirma que la República Argentina facilitará, de acuerdo a la legislación nacional y provincial, la consulta o participación de los extranjeros en las decisiones relativas a la vida pública y a la administración de las comunidades locales donde residan ${ }^{28}$.

En este sentido, es necesario aclarar que el escenario es complejo por la heterogeneidad de disposiciones, ya sea a nivel nacional, provincial y municipal. Argentina es un Estado con un gobierno republicano, representativo y de carácter federal. Hay que remitirse a leyes nacionales, provinciales y municipales para rastrear los derechos electorales. Específicamente en el país los extranjeros no pueden participar a través del voto en las elecciones nacionales. Los derechos políticos están reconocidos en todo el territorio nacional sólo para el nivel municipal, con matices por municipio. En todos ellos se ejerce, con mayores o menores dificultades de tipo burocrático-administrativas, el derecho a elegir todas las autoridades municipales. A nivel provincial este tema es aún más complejo porque difiere según la normativa de cada provincia, ya que en algunos casos como Córdoba, Buenos Aires, Tucumán y La Rioja han ampliado el derecho al voto de los extranjeros recientemente, hasta el nivel de autoridades del ejecutivo y legislativo provincial. De allí que este aspecto sigue siendo un gran desafío pendiente para el país como gran receptor de inmigrantes y en contextos internacionales y regionales de gran movilidad humana, se requiere repensar la ciudadanía en términos más abiertos e inclusivos. Esta extensión limitada de derechos políticos produce una restricción en el ejercicio de ciertos derechos políticos, sobretodo en la participación en los procesos de elección de representantes a nivel nacional y los perpetúa en una situación de desventaja frente a la mayoría. Aunque no limita otros derechos, como la elección a autoridades municipales o provinciales, según el caso (CALDERON CHELIUS, 2010).

\section{Limitaciones y desafíos que presenta la nueva Ley de Migraciones}

Los progresos en materia de derechos y de protección jurídica de los Derechos Humanos en Argentina, son notables. A su vez en este artículo se analizaron y corroboraron avances en cuanto al ejercicio y acceso efectivo de los derechos de los migrantes en determinados aspectos, tales como trabajo, educación y derecho al voto.

Al mismo tiempo existen limitaciones en cuanto al respeto de los Derechos Humanos en Argentina, es decir siguen existiendo situaciones de falta de respeto total o parcial a la legislación y las políticas públicas.

En este sentido, cabe destacar que muchos de los derechos reconocidos aún no pueden ejercerse por diferentes motivos tales como desconocimiento por parte de los inmigrantes o de los funcionarios públicos acerca de la nueva normativa, por la falta de su reglamentación y de una política de capacitación y sensibilización adecuada (CERRUTTI, 2012:7).

27. Para profundizar consultar Fuente: Elaboración de la Organización Internacional para las Migraciones (OIM) 2012 en base a información de la (DNM).

28. Mientras que (MARSHALL, 1950) plantea la evolución progresiva de los derechos ciudadanos: primero fueron los civiles, luego los políticos y finalmente, los sociales. En el caso de los migrantes, tal como sostiene Soysal (1994), la adquisición de derechos ha seguido una secuencia inversa a la planteada por Marshall, ya que los derechos económicos y sociales fueron los primeros que se otorgaron a los migrantes en los países receptores y la idea de otorgar derechos políticos a los inmigrantes es un planteamiento mucho más tardío y posterior a los derechos sociales y civiles. 
Además, los avances en cuanto a la actual normativa migratoria en muchas ocasiones no se refleja a nivel sociedad. En tanto persisten discursos, actitudes y comportamientos discriminatorios, xenófobos y racistas en el seno de la sociedad argentina, alentados desde algunos medios de comunicación y desde ciertos funcionarios y agentes del Estado en diferentes ámbitos y jurisdicciones dificultando el cumplimiento de los derechos de los migrantes. Reaparece con intensidad, la figura de la llamada inmigración limítrofe como problema social, se los hace responsables del desempleo e inseguridad del momento, situación que tendrá graves consecuencias en la vida cotidiana de los inmigrantes. Existe en la sociedad una mirada hostil hacia el migrante, que lo percibe como posible amenaza, peligro. Esta última situación se vio agravada a partir de la década de los 90 (GRIMSON, 2006) cuando en el país tiene lugar un cambio de la percepción social en torno a la migración limítrofe. ${ }^{29}$

De acuerdo a estudios realizados por el INADI ${ }^{30}$ (Instituto Nacional contra la Discriminación, Xenofobia y Racismo) el ámbito educativo es el espacio donde los migrantes sufren más experiencias discriminatorias. En segundo lugar, se encuentra el ámbito laboral, y por último; el transporte y la vía pública.

Desde determinados ámbitos del Estado -el Poder Ejecutivo principalmente-, se asociaron los problemas sociales y económicos del país a la inmigración, responsabilizando a los inmigrantes de países limítrofes de aquellos efectos provenientes de las políticas económicas implementadas bajo el neoliberalismo (desocupación, cólera, toma de viviendas, excesivos gastos sociales, aumento de la criminalidad, etc.). Esta construcción social y política del inmigrante limítrofe como amenaza contribuyó a dar legitimidad a políticas restrictivas y las prácticas de carácter persecutorio y represivo que se centraron particularmente en el inmigrante ilegal (DOMENENCH, 2011).
Además, la continuidad de trabas administrativos-burocráticas para acceder al Documento Nacional de Identidad $(\mathrm{DNI})^{31}$ y la falta de una política pública orientada a difundir el contenido de la nueva ley y a modificar las prácticas estatales que nacieron al amparo de la anterior ley, contribuyen a que no se respeten los derechos de este grupo social.

En efecto, los migrantes en Argentina continúan siendo un grupo en situación de vulnerabilidad, tal como lo demostrara el incendio de un taller textil en 2006 en el que murieron seis personas de nacionalidad boliviana que trabajaban en condiciones de semi esclavitud y otros hechos de semejantes características. A su vez, aún existe un predominio de trabajo precario y una elevada concentración ocupacional en nichos específicos (situación agravada en el caso de las mujeres), situaciones puntuales de trabajo esclavo, bajos niveles educativos.

\section{Vinculación entre la política migratoria argentina y la política del proceso de integración MERCOSUR}

Si bien el MERCOSUR se inició con una lógica empresarial de corte neoliberal, con el tiempo fue lentamente avanzando desde lo estrictamente comercial hacia cuestiones sociales y culturales, incluidas temáticas poblacionales y en particular las migratorias (NOVICK, 2005).

La cuestión migratoria se abordó desde el inicio mismo del proceso de integración ${ }^{32}$.En el marco orgánico del MERCOSUR los espacios que tratan la materia de las migraciones y la movilidad laboral desde sus diferentes perspectivas y con diversos niveles de desarrollo son: a) el Subgrupo No 10 de Asuntos Laborales, Empleo y Seguridad Social; b) la Comisión Sociolaboral del MERCOSUR; c) el Grupo de Liberalización del Comercio de Servicios;

29. Situación que no ocurre con la migración europea y sí se puede ampliar a países del Tercer Mundo, o países en guerra, musulmanes, africanos, etc.

30. INADI- Mapa Nacional de la Discriminación 2013.Segunda Serie de Estadísticas sobre Discriminación en Argentina.

31. Es de destacar que la carencia de documentación trae consigo problemas a los inmigrantes en su camino hacia la obtención de trabajos, y para lograr el respeto pleno de sus derechos laborales así como también para el acceso a otros servicios como el de la salud, la educación. Asimismo, la imposibilidad de obtener los certificados de estudios correspondientes que acrediten los niveles aprobados, obstaculiza la continuidad de los estudios (universitarios, terciarios) y las posibilidades de crecimiento, acentuando las condiciones de marginalidad y exclusión. (CERRUTI, 2012). 32. Los cuatro Estados fundadores del MERCOSUR, es decir Argentina, Brasil, Paraguay y Uruguay; más los Estados asociados, Chile y Bolivia, han suscrito y, en la mayoría de los casos, han ratificado instrumentos internacionales como la Convención Internacional Sobre la Protección de los Derechos de Todos los Trabajadores Migratorios y sus Familias, la Convención de Palermo y la Convención sobre el Estatuto de refugiados, situación que los ha obligado a incluir en sus agendas internas temas relacionados con la migración internacional. 
d) el Foro Consultivo Económico y Social; e) la Reunión de Ministros del Interior; y f) el recientemente creado Grupo "ad hoc" sobre Integración Fronteriza (ERMIDA URIARTE, 2009).

El tema de migraciones se incorpora, en los últimos años, en la agenda del MERCOSUR como una temática relevante. Y aunque su tratamiento y contenido de esta agenda han ido cambiando a lo largo del tiempo, se le fue otorgándole cada vez con mayor intensidad y mayor importancia.

El MERCOSUR está compuesto por diferentes países democráticos, inmersos en una lógica económica de integración para competir con otros mercados internacionales, de allí la necesidad de facilitar el flujo de migraciones, que por otra parte es una realidad permanente en la región. Al mismo tiempo el MERCOSUR y a pesar de mantener su status de unión aduanera imperfecta, asume a la migración intrarregional como un factor a considerar en su desarrollo económico y social, buscando reducir las asimetrías teniendo en cuenta el respeto de los derechos fundamentes de las poblaciones que integran este proceso. De allí que se evidencian avances en materia institucional con respecto a la incorporación de los Derechos Humanos a través de la creación en el 2004 de la Reunión de Altas Autoridades en Derechos Humanos (RAADH) y luego en 2009 con la creación del Instituto de Políticas Públicas en Derechos Humanos del MERCOSUR (IPPDH). ${ }^{33}$

Los avances en materia de políticas migratorias en el bloque son principalmente dos: el Acuerdo sobre Residen$\mathrm{cia}^{34}$ y el Foro Especializado Migratorio. La firma de dicho Acuerdo marca un punto de inflexión y un gran avance en materia migratoria ya que confirma los postulados de los tratados internacionales al buscar facilitar la movilidad, la residencia y la igualdad de derechos entre migrantes y na- cionales. El fin del acuerdo consiste en que los nacionales de un Estado parte que deseen residir en el territorio de otro Estado parte podrán obtener una residencia legal en este último. También se prevé la igualdad entre nacionales de los Estados parte del MERCOSUR, el derecho a reunificación familiar y el derecho a transferir remesas (Artículos 8 y 9). Este convenio es la norma más importante en materia migratoria en el ámbito de este proceso de integración hasta el momento.

Además cabe destacar como otro avance la creación del Foro Especializado Migratorio del MERCOSUR y Estados Asociados (FEM), que tiene entre sus funciones el estudio del impacto de las migraciones en la región y fuera de ella, el análisis y desarrollo de proyectos de normas y/o acuerdos en materia migratoria que regirán para los países del bloque.

El MERCOSUR cuenta con una estructura normativa que busca lograr el respeto de los Derechos Humanos de los trabajadores del bloque ${ }^{35}$ y a su vez consolidar la integración, ejemplo de esto es el ya mencionado Acuerdo sobre Residencia para nacionales de los Estados Parte del MERCOSUR, Bolivia y Chile. Entre otras disposiciones en el plano laboral establece el derecho a acceder a cualquier actividad, por cuenta propia o ajena en igualdad de condiciones con los nativos, de acuerdo a las normas de cada país (Artículo 8.2) y el trato no menos favorable que el que reciben los nacionales del país de recepción, en lo que concierne a la aplicación de la legislación labor especialmente en materia de remuneraciones, condiciones de trabajo y seguros sociales. También, cabe referir el Acuerdo Multilateral de Seguridad Social (firmado 1997, ratificado 2005), el cual se estableció con el propósito de regular las relaciones de seguridad social entre los países integrantes del MERCOSUR; por lo tanto, constituye una herramienta fundamental de gestión migratoria regional. Reconoce los

33. En este sentido cabe mencionar el rol protagónico del Instituto de Políticas Públicas en Derechos Humanos del MERCOSUR (IPPDH) el cual es una instancia intergubernamental creada en el 2009, por Decisión del Consejo del Mercado Común (CMC) 14/09. Tiene como funciones principales la cooperación técnica, la investigación, la capacitación, y el apoyo en la coordinación de políticas regionales de los Derechos Humanos. Disponible en: http://www.ippdh.mercosur.int/sobre-ippdh/

34. "El Acuerdo sobre Residencia, es el corolario de un intento por instrumentalizar la política migratoria común, es una herramienta con la que se pretende dar cause legal e institucional a la movilidad laboral en el MERCOSUR y permitir la libre residencia; pero en el camino se han presentado obstáculos para que lo aprobado en Brasilia, en 2002, "baje" a las leyes, reglamentos e instituciones de cada uno de los seis países. Si bien ya cuenta con la ratificación, en algunos casos muy tardía, por parte de los seis Estados firmantes; pero que aún falta por ser internalizar en el plano particular.” (MUÑOZ BRAVO, 2011)

35. En este sentido la referencia a la libre movilidad de trabajadores (y personas) en el origen del MERCOSUR aparece implícita en el Acta de Asunción, al referirse a la libre circulación de factores como una de las implicancias del mercado común Artículo 1. No existe sin embargo, referencia directa a la cuestión laboral, ni fue señalada como objetivo programático en la conformación del bloque. 
mismos derechos y obligaciones que los nacionales a los trabajadores (nacionales o no de MERCOSUR) que presten o hayan prestado servicios en los Estados parte, a su vez, se identifican los mismos derechos a sus familiares y asimilados.

Finalmente, la Declaración Sociolaboral (firmada 1998), resolución que, si bien no es vinculante, incluye amplios principios y derechos en el área del trabajo. Garantiza la igualdad efectiva de derechos y oportunidades en el empleo de los trabajadores y afirma que todo trabajador migrante, independientemente de su nacionalidad, tiene derechos en igualdad de condiciones de trabajo que los reconocidos a los nacionales.

Con respecto al derecho a la educación también se constatan ciertos avances en el marco del Sistema Educativo MERCOSUR, el cual tiene como fin profundizar la integración. Por un lado, a través de la formación de un aparato burocrático que respalda dichos objetivos. Y por otro lado, a través de diferentes acciones tales como la puesta en marcha de programas focalizados tanto en educación básica, media y superior, políticas regionales en la acreditación de títulos, programas de movilidad, espacios de encuentro, el inicio de actividades de formación docente.

Por último, y a pesar que aún no se visualizan avances concretos en materia de derechos políticos, cabe mencionar que el Consejo del Mercado Común (CMC) aprobó en diciembre de 2010 un Plan de Acción para la configuración progresiva de un Estatuto de la Ciudadanía del MERCOSUR que demanda a los diversos consejos de ministros, foros e instancias de integración la puesta en marcha de un cronograma de 10 años para la concreción de una serie de beneficios de una ciudadanía común. El Plan aún no ha entrado en vigencia (se prevé que lo haga para el año 2021) y tiene como objetivo garantizar a todos los ciudadanos del territorio una cantidad de derechos, de residencia, trabajo, educación, salud y a la libre circulación (CERIANI CERNADAS, 2012).

El MERCOSUR y los países asociados se posicionan en un lugar central y pueden destacarse importantes repercusiones: a fines de 2007, Chile inicia un masivo plan destinado a regularizar la situación de aquellos que hubieren ingresado hasta el 21 de octubre del 2007; en 2008, Uruguay adopta la política de "puertas abiertas", aprobando una nueva legislación No 18.250 que entiende también el derecho a migrar como derecho humano; Brasil ajustó sus regulaciones administrativas para la admisión de extranjeros y en el 2009 aprobó una amnistía. Es decir, las reformas legales ocurridas principalmente en Argentina y
Uruguay, así como la prevista en Brasil, insinúan una tendencia a concebir el derecho a migrar como un derecho humano integral, lo cual ha llevado a que se establezca la protección de ciertos derechos (educación y salud) aun para quienes se encuentren en situación migratoria irregular.

Al mismo tiempo que se perciben avances en el MERCOSUR en cuanto a una política migratoria más abierta que reconoce los Derechos Humanos, se enfrenta un gran desafío ya que existen países que pertenecen al bloque que siguen manifestando muchas reticencias al cambio de políticas más abiertas, tal como el caso de Paraguay, que aún no ha modificado su legislación migratoria. Y el caso de Brasil, que se encuentra en proceso de elaboración de nuevas legislaciones migratorias. En consecuencia y desde el derecho interno de cada Estado, resulta imperioso armonizar el marco jurídico para la difusión y el conocimiento de los derechos fundamentales de los migrantes y así evitar situaciones discriminatorias, en interacción con las competencias de cada Estado para establecer normas relativas al control de sus fronteras y a su organización interna.

\section{Conclusiones}

La política migratoria argentina está interrelacionada con los instrumentos migratorios del proceso de integración MERCOSUR y se adecuó de manera paulatina y progresiva a los estándares internacionales de Derechos Humanos, durante el período 2003-2013. Al mismo tiempo se ponen de manifiesto los límites y desafíos al interior del MERCOSUR en materia migratoria.

En primer lugar el cambio de la política migratoria Argentina hacia una más abierta que hace hincapié en el reconocimiento de los derechos de los migrantes, marca un punto de inflexión con el período anterior. En tanto la ley reconoce al derecho a migrar como un derecho humano en su artículo 4 y la participación del Estado como garante de dichos derechos.

En segundo lugar, la importancia de tal cambio reside en que este país es el principal receptor de migrantes provenientes de países limítrofes, de allí la relevancia y el impacto de sus políticas.

Al mismo tiempo esta transformación de políticas se manifestó en el activo rol que ocupó el país en este período, impulsando entre otras medidas, la puesta en marcha del Programa Patria Grande y la regularización de la situación 
de muchos migrantes mercosureños, mejorando las condiciones concretas de vida.

En tercer lugar, a partir del trabajo de investigación realizado, se pueden observar avances concretos en la implementación y el efectivo reconocimiento de ciertos derechos (tales como trabajo-educación y derecho al voto).

Finalmente, es un gran desafío pendiente el de seguir avanzando y profundizando el proceso de integración en relación a las políticas migratorias comunes, y más aún que sea abierta en relación al respeto de los derechos fundamentales

Las características normativas e institucionales propias del MERCOSUR y relacionadas con la falta de supranacionalidad, terminan chocando con las diferentes particularidades y realidades de los distintos países que integran el proceso de integración y hacen que se les confiera mayor jerarquía a las leyes locales que a las disposiciones emanadas por el bloque. Esta falta de armonización y coherencia de las políticas públicas migratorias, involucradas en la formulación e instrumentación de dichas normativas, al interior del MERCOSUR, terminan obstaculizando el efectivo respeto de los derechos fundamentales de los migrantes en la región.

Cabe resaltar que el actual gobierno de Mauricio Macri tomó recientemente algunas medidas a través de un decreto en relación a la política migratoria que modifican y endurecen las exigencias para el ingreso de extranjeros con antecedentes penales, al tiempo que simplifica los trámites para la expulsión de aquellos que delincan. También se creará una policía abocada a controlar las fronteras. Dichas medidas tienen como objetivo tal como anuncia el Presidente evitar que el crimen internacional elija el país para delinquir.

Si bien estas decisiones son muy recientes y, por lo tanto, difíciles de evaluar, sí se encuentran en sintonía con las políticas que en diferentes oportunidades se han tomado en el gobierno de la Ciudad de Buenos Aires que han intentado responsabilizar o al menos vincular la migración con los problemas sociales que atraviesa el país. De lo expuesto se desprende una línea de continuidad en cuanto a la gestión. Cabe aclarar que el gobierno de la CABA estaba a cargo el actual presidente argentino Mauricio Macri (2007-2015).

A su vez el gobierno actual se encamina y sigue con la corriente internacional caracterizada por políticas migratorias más restrictivas.
La situación actual refuerza la tendencia mundial en materia de políticas migratorias restrictivas o de control, tal es el caso de Estados Unidos como el de la Unión Europea. Las fuertes declaraciones del presidente de Estados Unidos, Donald Trump, en relación a la política migratoria, tales como son sus afirmaciones acerca de la construcción de un Muro con la frontera de su país vecino, México y la deportación de latinos. Al mismo tiempo la Unión Europea se caracteriza por imponer cada vez más barreras a la migración, así como a criminalizar la condición de irregularidad migratoria, hechos que han tenido graves consecuencias en las condiciones de traslado y de vida de los migrantes. Existen en la actualidad numerosos ejemplos de violaciones a los Derechos Humanos de las personas migrantes, para quienes su principal motivación ha sido intentar alcanzar una vida mejor para sí mismos y sus familias.

A todo esto se le suman actitudes xenófobas y racistas en contra de los migrantes especialmente islámicos en los países del Norte, agravada a partir de los diferentes atentados producidos recientemente en 2017 en Estados Unidos, Australia, el Reino Unido, en 2005 en Francia el ataque contra la sede de la revista Charlie Hebdo y en Dinamarca otro atentado con similares características. Dicha situación no hace más que recrudecer la tendencia de las políticas migratorias, con una lógica que concibe al migrante como amenaza a la seguridad nacional de estos países. A esto se le suma el surgimiento de partidos políticos que capitalizan y alimentan estos elementos xenófobos de las sociedades.

Es importante reflexionar que tratar el tema de Derechos Humanos requiere de una participación por parte de todos los actores siendo los Estados, el principal garante de dicha protección, y otros actores de la sociedad civil que interactúan para garantizarlos.

En este sentido Salil Shetty, Secretaria General de Amnistía Internacional en la presentación del Informe 2013 sobre la situación de los Derechos Humanos en el mundo, afirmó "La pasividad mundial en el terreno de los derechos humanos está convirtiendo el mundo en un lugar cada vez más peligroso para las personas refugiadas y migrantes". 


\section{Bibliograffia}

BAER G., BENITEZ, N. y CONTARTESE, D. (2012) "La participación de los trabajadores inmigrantes procedentes de países limítrofes y de Perú en los mercados laborales urbanos de Argentina" en El impacto de las migraciones en Argentina. Cuadernos Migratorios No2, OIM.

CALDERON CHELIUS, L. (2010) "Migración Latinoamericana y Derechos Políticos transnacionales. El proceso de extensión del voto en el exterior" En Patrones migratorios internacionales en América Latina, Eudeba, Buenos Aires

CERIANI CERNADAS, P. (2011) “Luces y sombras en la legislación migratoria Latinoamericana"

CERIANI CERNADAS, P. (2012) "Apuntes críticos sobre derechos humanos, migraciones y libre circulación de personas en el MERCOSUR", En Revista de Derechos Humanos. Reflexiones desde el Sur, Ministerio de Justicia y Derechos Humanos de la Nación y Sistema Argentino de Información Jurídica (Infojus).

CERRUTTI, M. (2012) "Derechos Sociales, Mercado de trabajo y Migraciones Internacionales en Argentina” En Informe Nacional sobre Desarrollo Humano, del Programa de Naciones Unidas para el Desarrollo (PNUD Argentina), Centro de Estudios de Población (CENEP) y Consejo Nacional de Investigaciones Científicas y Técnicas (CONICET), Buenos Aires, BP12-02.

DE LUCAS, J. (2004) “Globalización migraciones y derechos humanos. La inmigración como res política”, En Cuadernos Electrónicos de Filosofía del Derecho, Universidad de Valencia. №10.

ERMIDA URIARTE, O., (2009) "Derecho a migrar y derecho al trabajo" en Las migraciones humanas en el MERCOSUR: una mirada desde los derechos humanos. Observatorio de Políticas Públicas de Derechos Humanos en el MERCOSUR, Uruguay.

GRIMSON, A. (2006). "Nuevas xenofobias, nuevas políticas étnicas en la Argentina" en Grimson, Alejandro y Jelin, Elizabeth (comps.) Migraciones regionales hacia la Argentina. Diferencia, desigualdad y derechos, Buenos Aires: Prometeo.

INADI, (2013) “Mapa Nacional de la Discriminación 2013”, Segunda Serie de Estadísticas sobre Discriminación en Argentina

Informe sobre Desarrollo Humano (2014) "Sostener el Progreso Humano: reducir vulnerabilidades y construir resiliencia” (PNUD)

MAGUID, A. (2005) "La migración internacional en el escenario del MERCOSUR: cambios recientes, asimetrías socioeconómicas y polí- 
ticas migratorias". En: Estudios Migratorios Latinoamericanos, Vol.19, Número 57.

MARMORA, L. (1988) "La fundamentación de las políticas migratorias internacionales en América Latina" En: Estudios Migratorios Latinoamericanos, No10, CEMLA, Buenos Aires

MARSHALL, T. (1950) "Citizenship and Social Class" En MARSHALL, Thomas y BOTTOMORE, Tom Citizenship and Social Class, Pluto Press, Londres

MASSEY, D. et alt (1993) "Theories of International migration: Review and appraisal" En Population and Development Review, Vol. 19, №3, New York.

MUGUERZA, J. (1989) "La alternativa del disenso", En MUGUERZA Javier y PECES BARBA, G. (coord.), Los fundamentos de los derechos fundamentales, Debate, Madrid.

MUÑOZ BRAVO T. M., (2011) “El proceso de internalización del Acuerdo sobre Residencia en el MERCOSUR: Una evaluación del compromiso de seis Estados de crear un área de libre residencia y trabajo", Disponible en: http://www.mintra.gob.pe/migrante/pdf/Aplicacion Acuerdo Residencia MERCOSUR.pdf

NOVICK, S. (2007) "Políticas y actores sociales ante la emigración de argentinos" En Sur-Norte. Estudios sobre la emigración reciente de argentinos. Ed. Catálogos y Universidad de Buenos Aires, editores, Instituto de Investigaciones Gino Germani, Buenos Aires.

NOVICK, S. (2004) "Una nueva ley para un nuevo modelo de desarrollo en un contexto de crisis y consenso", En GIUSTINIANI, R. Migración: un derecho humano, Editorial Prometeo, Buenos Aires.

NOVICK, S. (2005) "La reciente política migratoria argentina en el contexto del MERCOSUR” En NOVICK, Susana; HENER, Alejandro y DALLE, Pablo. El proceso de integración MERCOSUR: de las políticas migratorias y de seguridad a las trayectorias de los inmigrantes, Documento de Trabajo No 46, Instituto de Investigaciones Gino Germani, Facultad de Ciencias Sociales, Universidad de Buenos Aires, Buenos Aires.

NOVICK, S. (2006) "MERCOSUR y migraciones: el caso argentino". Trabajo presentado en el II Congreso de la Asociación Latinoamericana de Población, Guadalajara, México.

NOVICK, S. y OTEIZA, E. (2000). "Inmigración y derechos humanos. Política y discurso en el tramo final del menemismo". Buenos Aires: Instituto Gino Germani, Documento de Trabajo Nro. 14, febrero de
2000

OIM, (2012) "Perfil migratorio de Argentina”, Buenos Aires.

PEREZ LUÑO, A. (1988) Los derechos fundamentales. Tecnos Madrid. (citado por MUGUERZA, J. (1989) "La alternativa del disenso", En MUGUERZA, Javier y PECES BARBA, G. (coord.) Los fundamentos de los derechos fundamentales, Debate, Madrid, pág. 19).

SOYSAL, Y. (1994) Limits of citizenship, Migrants and Postnational Membership in Europe. University of Chicago Press, Chicago.

TEXIDÓ, E. (2008). “Perfil migratorio de Argentina”, elaborado para la OIM, Buenos Aires.
Recibido 07/06/2017 - Aceptado 27/02/18 


\section{Refugiados en América Latina: un análisis de los avances normativos para su protección en la región ${ }^{\star}$}

\section{- Resumen}

Este trabajo tiene como objetivo, analizar cuáles han sido los avances que se han producido en América Latina con respecto al tratamiento jurídico de los refugiados a partir de la cooperación entre los países de la región y destacar de este modo, el rol de la cooperación sur-sur en materia de derechos humanos. A fin de alcanzar dicho objetivo se realizan algunas precisiones conceptuales, se hace un recorrido por los antecedentes históricos del derecho internacional de los refugiados y una breve mención de los instrumentos internacionales en la materia. Finalmente, se profundiza en el tratamiento de los refugiados en América Latina y Argentina como un ejemplo de la aplicación de dichos avances.

\section{- Palabras Clave}

Refugiados, América Latina, Cooperación, derechos humanos, Argentina.

\section{Inglés | English}

\section{- Abstract}

This article focuses on legal advances in refugees' protection in Latin America and the role of South-South cooperation on this topic. It defines some important concepts as refuge, asylum and asylum-seeker. Then it mentions historical antecedents on International Refugee Law. Ultimately, the article analyses the legal treatment of refugees in Latin America and Argentina from a human right perspective.

\section{- Key words}

Refugees, Latin America, cooperation, Human Rights, Argentina.

* Se agradece especialmente los aportes realizados por Lidia Gatti a fin de realizar este trabajo.

${ }^{* *}$ Licenciada en Relaciones Internacionales (UNR) y miembro del Observatorio de Política Exterior Argentina (OPEA). 